Article

\title{
Safe vs. Fair: A Formidable Trade-off in Tackling Climate Change
}

\author{
Massimo Tavoni $^{1,2, *}$, Shoibal Chakravarty ${ }^{2}$ and Robert Socolow ${ }^{2,3}$ \\ 1 Fondazione Eni Enrico Mattei (FEEM) and Euro-Mediterranean Center on Climate Change \\ (CMCC), Corso Magenta 63, 20123 Milano, Italy \\ 2 Princeton Environmental Institute, Princeton University, Nassau Hall, Princeton, NJ 08544, USA; \\ E-Mail: shoibalc@princeton.edu \\ 3 Department of Mechanical and Aerospace Engineering, Princeton University, Princeton, NJ 08544, \\ USA; E-Mail: socolow@princeton.edu \\ * Author to whom correspondence should be addressed; E-Mail: mtavoni@princeton.edu; \\ Tel.: +39-0252-036-936; Fax: +39-0252-036-946.
}

Received: 7 December 2011; in revised form: 10 January 2012 / Accepted: 19 January 2012 / Published: 6 February 2012

\begin{abstract}
Global warming requires a response characterized by forward-looking management of atmospheric carbon and respect for ethical principles. Both safety and fairness must be pursued, and there are severe trade-offs as these are intertwined by the limited headroom for additional atmospheric $\mathrm{CO}_{2}$ emissions. This paper provides a simple numerical mapping at the aggregated level of developed $v s$. developing countries in which safety and fairness are formulated in terms of cumulative emissions and cumulative per capita emissions respectively. It becomes evident that safety and fairness cannot be achieved simultaneously for strict definitions of both. The paper further posits potential global trading in future cumulative emissions budgets in a world where financial transactions compensate for physical emissions: the safe $v s$. fair tradeoff is less severe but remains formidable. Finally, we explore very large deployment of engineered carbon sinks and show that roughly $1,000 \mathrm{Gt} \mathrm{CO}_{2}$ of cumulative negative emissions over the century are required to have a significant effect, a remarkable scale of deployment. We also identify the unexplored issue of how such sinks might be treated in sub-global carbon accounting.
\end{abstract}

Keywords: climate policy; burden sharing; negative emissions 


\section{Introduction}

Climate change is recognized as one of the most challenging problems that the world faces today. At the same time, only limited progress has been achieved at the national and international level to address it. Nations have found it difficult to manage the atmosphere as a common property resource. They have been unable to distribute responsibilities among themselves for mitigation actions, and they have been reluctant to adopt unilateral policies, which they view as ineffective or even counterproductive. As a result, the stock of greenhouse gases in the atmosphere continues to rise. Since the Kyoto protocol of 1997, the atmospheric concentration of $\mathrm{CO}_{2}$ alone has increased by about 25 parts per million, to more than $390 \mathrm{ppm}$. The coming decades will test the world's ability to decide how much needs to be done and who has to do what.

We assume that avoiding dangerous climate change and addressing the issue of responsibility and equity in $\mathrm{CO}_{2}$ emissions are the two fundamental pillars on which comprehensive climate change legislation will be based [1]. Henceforth, we refer to these two as "safety" and "fairness". The extent to which safety and fairness are mutually realizable and can be attained simultaneously will depend on future policies, institutions and technology, as well as the extent to which fossil fuels remain attractive. At the moment, this challenge appears immense [2].

Equity and responsibility are repeatedly invoked to convey the obligations of the developed world in terms of mitigation action. Yet, researchers and policy makers discuss these objectives largely without reference to their interactions with the stringency of climate policy. This paper seeks to remedy this omission by demonstrating how fairness in its various guises is intertwined with safety. The strategy adopted is to use the same physical concept, "cumulative emissions," to express both fairness and safety. Fairness is explored at the aggregated level of developed vs. developing countries. We focus on $\mathrm{CO}_{2}$ emissions and ignore emissions of other greenhouse gases and aerosols [3]. We consider both energy [4] and land-use change emissions [5].

Cumulative emissions of $\mathrm{CO}_{2}$ connect to safety through the concept of $\mathrm{CO}_{2}$ "headroom." Headroom is defined as the difference between the maximum amount of $\mathrm{CO}_{2}$ in the atmosphere judged to be safe (the "safety cap") and the amount already in the atmosphere. The safety cap can be linked to equilibrium temperature rise, and, consequently, expected damage. Headroom becomes smaller when climate stabilization targets become more stringent. The lower stabilization targets that have been emphasized in the past few years produce less headroom and thereby tighten the entanglement of safety and fairness.

Cumulative emissions connect to fairness when the atmosphere is viewed as a common property resource shared by all humans: In this version of fairness, all individuals have an equal right to $\mathrm{CO}_{2}$ emissions in the atmosphere. This definition derives from (1) the right to economic growth and a better standard of living, and (2) the strong observed correlation between economic growth and $\mathrm{CO}_{2}$ emissions. The fairness principle provides equal cumulative emissions to all, starting at a particular date. It should be noted that there is still a wide range of emissions possible for the same level of economic well-being: In Japan and Western Europe, per capita emissions are half that of the US for a lifestyle that is quite similar. This version of fairness needs to be supplemented with a decision about which people, past and future, should be included. In this paper we show quantitatively the consequences of specific inclusion rules. The historical dimension of this principle of fairness 
addresses the responsibility of future damage to some people due to the past emissions of others. However, it is simplistic for the redress of such damage to take the form of exactly equating future and past emissions. Significant advances have been made in increasing the efficiency of energy services and in making energy infrastructure less carbon intensive. Nonetheless, this paper investigates the challenges of simultaneously considering this narrow definition of fairness with various degrees of climate safety.

\section{Quantifying Safety Using Global Cumulative Emissions}

Our definition of climate safety is parametrized by a target expressed as a maximum rise in the earth's average global surface temperature. Recent work suggests that a relatively well-defined probabilistic linear relationship connects cumulative emissions and the rise in this temperature. Each $1,000 \mathrm{GtCO}_{2}$ of cumulative emissions since pre-industrial times (here, year 1850) and extending indefinitely into the future produces, as the central value of the temperature distribution, roughly a half degree Celsius rise (more precisely, $0.48^{\circ} \mathrm{C}$ ). Moreover, the temperature rise associated with $1,000 \mathrm{GtCO}_{2}$ of emissions has a $90 \%$ probability of being in the interval between $0.27^{\circ} \mathrm{C}$ and $0.68{ }^{\circ} \mathrm{C}[6,7]$. In IPCC parlance, values falling in this $90 \%$ confidence interval are called "very likely". This linear relationship allows us to use cumulative emissions as a quantitative metric for safety. Because the "very likely" range is quite wide, the desired level of risk aversion for a given temperature target (like " $2{ }^{\circ} \mathrm{C}$ ") strongly affects the cumulative emission target [8].

We consider four global cumulative emissions budgets: 1,000, 2,000, 3,000 and 4,000 $\mathrm{GtCO}_{2}$ of "future" cumulative emissions, where the year 2005 divides past from future. Table 1 reports the central value of the temperature distribution and the "very likely" range for these four emission budgets, obtained from the rules above and accounting for the $1,800 \mathrm{GtCO}_{2}$ that was emitted in the atmosphere prior to 2005. The carbon budgets in Table 1 appear to be more permissive than budgets analyzed with integrated assessment models. Budgets meeting a 450 ppm-equivalent concentration target have traditionally been associated with the $2{ }^{\circ} \mathrm{C}$ objective. The IPCC Representative Concentration Pathway RCP 3-PD(2.6) generated by the IMAGE model [9], for example, foresees a future cumulative $\mathrm{CO}_{2}$ budget of about $1,500 \mathrm{GtCO}_{2}$ [10]. Values of temperature increase in Table 1 range from $0.8{ }^{\circ} \mathrm{C}$ to $4.0{ }^{\circ} \mathrm{C}$. The $1,000 \mathrm{GtCO}_{2}$ is the only budget that achieves the $2{ }^{\circ} \mathrm{C}$ signpost with "very likely' probability. The models involved in the EMF22 international scenarios have, on average, only $1,100 \mathrm{GtCO}_{2}$ of future cumulative emissions [11]. To compare integrated assessment models directly with the models whose outputs produced the simplified assumptions leading to Table 1, however, one must run the integrated assessment models beyond 2100, after which time cumulative emissions will continue to increase and surface temperature will continue to rise, As a result, a direct comparison is not possible. Moreover, all these models feature simplified carbon cycle modules, and each is simplified in its own way.

The relation between cumulative carbon emission and climate change measured by temperature increase is shown graphically in Figure 1. The twelve entries in Table 1 are shown as dots superimposed on a color-coded scale for global mean temperature change. 
Table 1. Cumulative $\mathrm{CO}_{2}$ emissions after 2005 and corresponding maximum-temperature increase above pre-industrial. The central value and top and bottom of the "very likely" range are shown, where "very likely" is the centered $90 \%$ interval of the distribution.

\begin{tabular}{ccccc}
\hline $\begin{array}{c}\text { Future } \\
\text { cumulative } \\
\text { emissions }\end{array}$ & $\begin{array}{c}\text { Temperature } \\
\text { Increase } \\
\text { (bottom 5\%) }\end{array}$ & $\begin{array}{c}\text { Temperature } \\
\text { Increase } \\
\text { (central value) }\end{array}$ & $\begin{array}{c}\text { Temperature } \\
\text { Increase } \\
\text { (top 5\%) }\end{array}$ & $\begin{array}{c}\text { Probability of not } \\
\text { exceeding 2 }{ }^{\circ} \mathbf{C}\end{array}$ \\
\hline $\mathrm{GtCO}_{2}$ & ${ }^{\circ} \mathrm{C}$ & ${ }^{\circ} \mathrm{C}$ & ${ }^{\circ} \mathrm{C}$ & $\%$ \\
1,000 & 0.8 & 1.3 & 1.9 & more than $95 \%$ \\
2,000 & 1.0 & 1.8 & 2.5 & just above $50 \%$ \\
3,000 & 1.3 & 2.3 & 3.3 & just below $50 \%$ \\
4,000 & 1.6 & 2.8 & 4.0 & somewhat above $5 \%$ \\
\hline
\end{tabular}

Figure 1. The relationship between cumulative $\mathrm{CO}_{2}$ emissions and equilibrium temperature rise (color coded, values in Centigrade). The middle line (labeled 50\%) is the central value corresponding to the mean of the probability distribution function (p.d.f.) of temperature rise and the two outer lines correspond to the very likely range $(5 \%-95 \%)$.

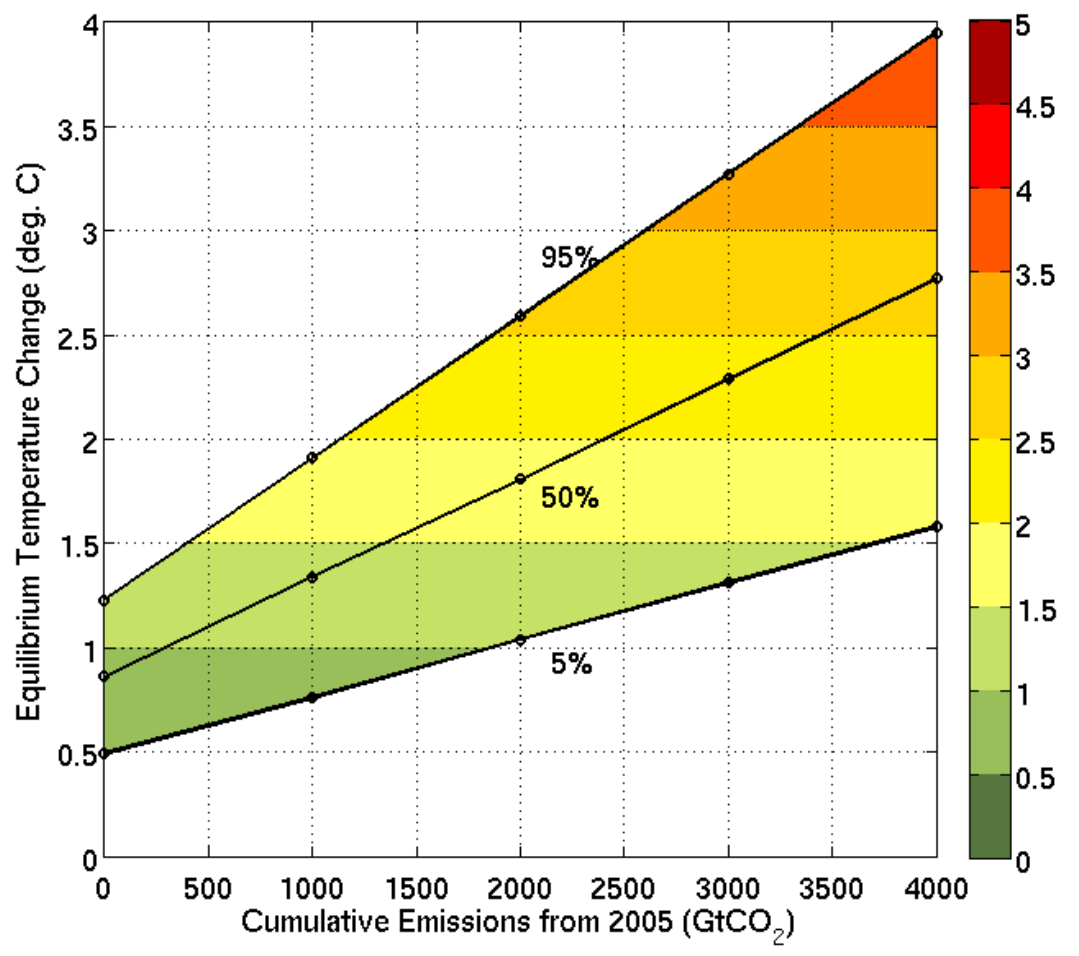

\section{Quantifying Fairness Using Per Capita Cumulative Emissions}

To include "fairness" in this formalism, we now move to a regional analysis at the highly aggregated level of developed versus developing countries, or, in this instance, the two UNFCCC categories of Annex I and Non-Annex I countries in the United Nations Framework Convention on Climate Change [12]. A global future cumulative emissions budget is the fixed sum of Annex I and Non-Annex 1 future cumulative emissions ( $A$ and $N$, respectively). The sum is a simple straight line- 
the "safety line" in a chart like Figure 2, which plots the Annex I carbon budget on the horizontal axis and the Non Annex I budget on the vertical axis.

\section{Global Future Cumulative Emission Budget $=A+N$}

The $(0,0)$ point on the plot corresponds to 2005 . When one moves along one of the four safety lines up and to the left of the diagram, global emissions remain equal to one of the four selected carbon budgets $\left(1,000,2,000,3,000\right.$ or 4,000 $\left.\mathrm{GtCO}_{2}\right)$, but emissions from Annex I are replaced by emissions from Non-Annex I. The safety lines intersect the vertical and the horizontal axes at the values reported in the first column of Table 1. With this mapping the reader can consider safety and fairness simultaneously. Once the reader has expressed a preference for a given safety line, the remaining choice is how to distribute the global carbon budget between Annex I and Non-Annex I.

Consider the simple case where the budget of future emissions is distributed according to population. We approximate the regional populations with values close to the United National population projections for 2050: 7.5 billion people in Non-Annex I and 1.5 Billion people for Annex I [13]. Thus, five-sixths of future emissions are assigned to Non-Annex 1; currently Annex I and Non-Annex I emissions are roughly equal. In Figure 2, emissions allocations for this case and our four specific targets appear as four black diamonds that fall on the line with a slope of 5, the population ratio. Note that we constrain cumulative emissions, not emissions at some future time: those who emit more now must eventually emit less to have cumulative emissions balance out. In our work, the end date for cumulative emissions is not specified. A large literature ("Contraction and Convergence") explores convergence in per capita emissions and equality after a specific date [14].

Figure 2. Safety lines for four global cumulative $\mathrm{CO}_{2}$ emissions targets after 2005 $\left(\mathrm{GtCO}_{2}\right)$. The lines are labeled by the targets- $-1,000 \mathrm{GtCO}_{2}$, etc. The color coded temperature rise corresponding to low temperature sensitivity ( $5 \%$ of p.d.f.) is shown in panel (a), mid-range temperature sensitivity ( $50 \%$ of p.d.f.) is shown in panel (b) and the high temperature sensitivity (95\% of p.d.f.) is shown in panel (c). The line labeled "2005," beginning at the point $(0,0)$, show Annex I and Non-Annex I shares proportional to population. Note that the scales are distorted such that a line at 45 degrees corresponds to a slope of 5.
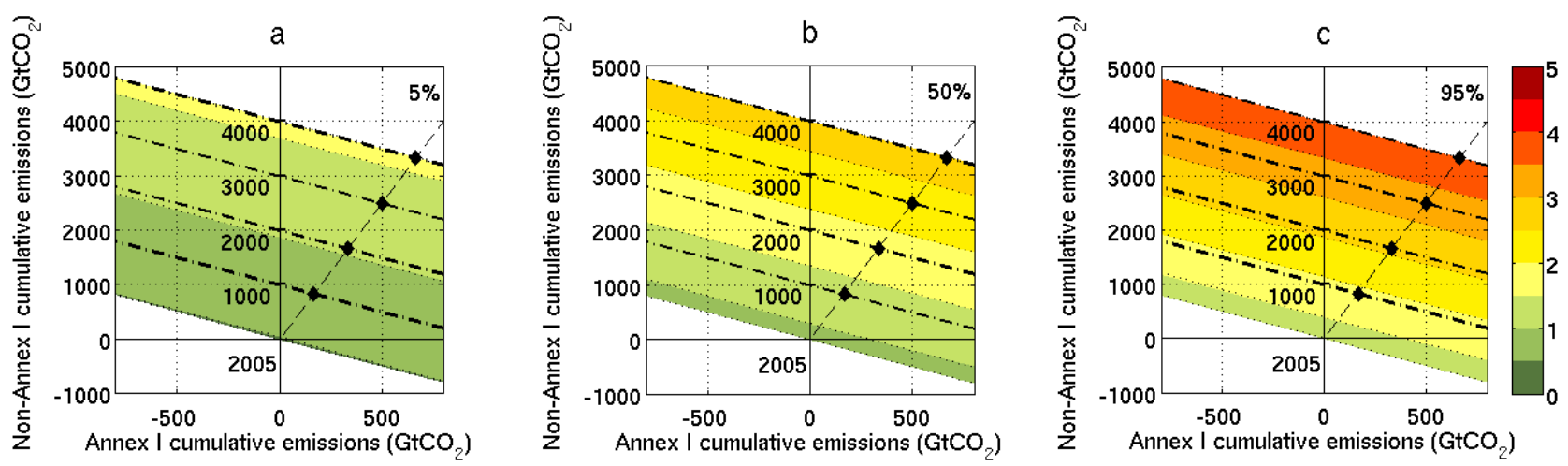

The principle of equal per capita emissions is widely invoked, which is why it is at the core of this paper. Applications of per capita rules to climate have been criticized on the grounds that they are not 
linked to the damages of global warming, for which a better focus would be compensation, not emissions. Moreover, per capita rules embody naïve assumptions about the capacity and willingness of governments to allocate on a per capita basis, rather than to sustain privilege [15]. The distinction between fairness to individuals and to nations figures prominently in a previous paper written by the three of us and three co-authors [16] (See [17] for a similar approach that also takes into account historical emissions.). It provides a framework for calculating the distribution of global emissions across all the world's individuals and identifying low and high emitters in both rich and poor states. Yet, the equity of rights applied at the national level remains a politically powerful ethical principle.

\section{Accounting for Historical Emissions}

Many commentators have supported the inclusion of historical emission rights in international climate agreements [18-23]. Similarly, several versions of burden-sharing have been recently proposed that involve scoring both past and future national $\mathrm{CO}_{2}$ emissions and that require equalized per capita emissions [24-30].

A generalization of the simple example above takes into account historical emissions for the same two groups of nations. We equalize cumulative per capita emissions inclusive of historical emissions beginning at some date. We consider three different start dates: 1850, 1950, and 1990. These choices account, respectively, for all historical emissions, for emissions only after the Second World War, and for emissions only after the reference year defined in the UN Framework Convention of 1992. We use the notation ECPC1850 to refer to an allocation of future emissions based on Equal Cumulative Per Capita emissions beginning in 1850, and similarly for other start times. The simple example shown in Figure 2 becomes an application of ECPC2005, which ignores historical emissions.

The required emissions data are shown in Table 2. Between 1850 and 2005, Annex I countries emitted almost $1,000 \mathrm{GtCO}_{2}$ to the atmosphere, roughly one-third more than Non-Annex I countries [31]. In the final 15 years of that interval, between 1990 and 2005, one fourth of all the global emissions between 1850 and 2005 occurred, and aggregate emissions in the two parts of the world were roughly equal.

Table 2. Historical cumulative emissions of $\mathrm{CO}_{2}$ (through 2005) from the world, Annex I and Non-Annex I $\left(\mathrm{GtCO}_{2}\right)$.

\begin{tabular}{cccc}
\hline Accounting Regimes & World & Annex I & Non-Annex I \\
\hline $1850-2005$ & 1,780 & 990 & 690 \\
$1950-2005$ & 1,190 & 660 & 530 \\
$1990-2005$ & 450 & 220 & 230 \\
\hline
\end{tabular}

Figure 3 shows the fairness lines consistent with the ECPC principle. Figure 3 has the same coordinates as Figure 2, with future cumulative emissions from Non-Annex 1 and Annex-1 as its axes. To understand the lines plotted on Figure 3 algebraically, define $N H$ and $A H$ as the historical emissions between some start date (say, 1950) and 2005, for Non-Annex I and Annex-I, respectively. The ECPC principle becomes:

$$
N+N H=5(A+A H)
$$


Figure 3. Fairness lines for cumulative $\mathrm{CO}_{2}$ emissions after $2005\left(\mathrm{GtCO}_{2}\right)$, for Annex I and Non-Annex I, under four ECPC schemes. Blue diamonds identify the points corresponding to different starting dates (which label these lines). The 16 black diamonds correspond to intersections of four values of future $\mathrm{CO}_{2}$ emission budgets with the four fairness lines discussed in the text. For example, the black diamond corresponding to the intersection of the 1990 ECPC line and the 2000 safety line states that the ECPC scheme beginning 1990 for a cumulative emissions target of $2,000 \mathrm{GtCO}_{2}$ allots future cumulative emissions of $187 \mathrm{GtCO}_{2}$ to Annex I and $1,813 \mathrm{GtCO}_{2}$ to Non-Annex I. The three red diamonds show the EIA's Business as usual projections for cumulative emissions from Annex I and Non-Annex I. The color coded contour labeled 50\% shows the mean temperature rise, the contours labeled $5 \%$ and $95 \%$ show the very likely temperature range for different cumulative emission targets.

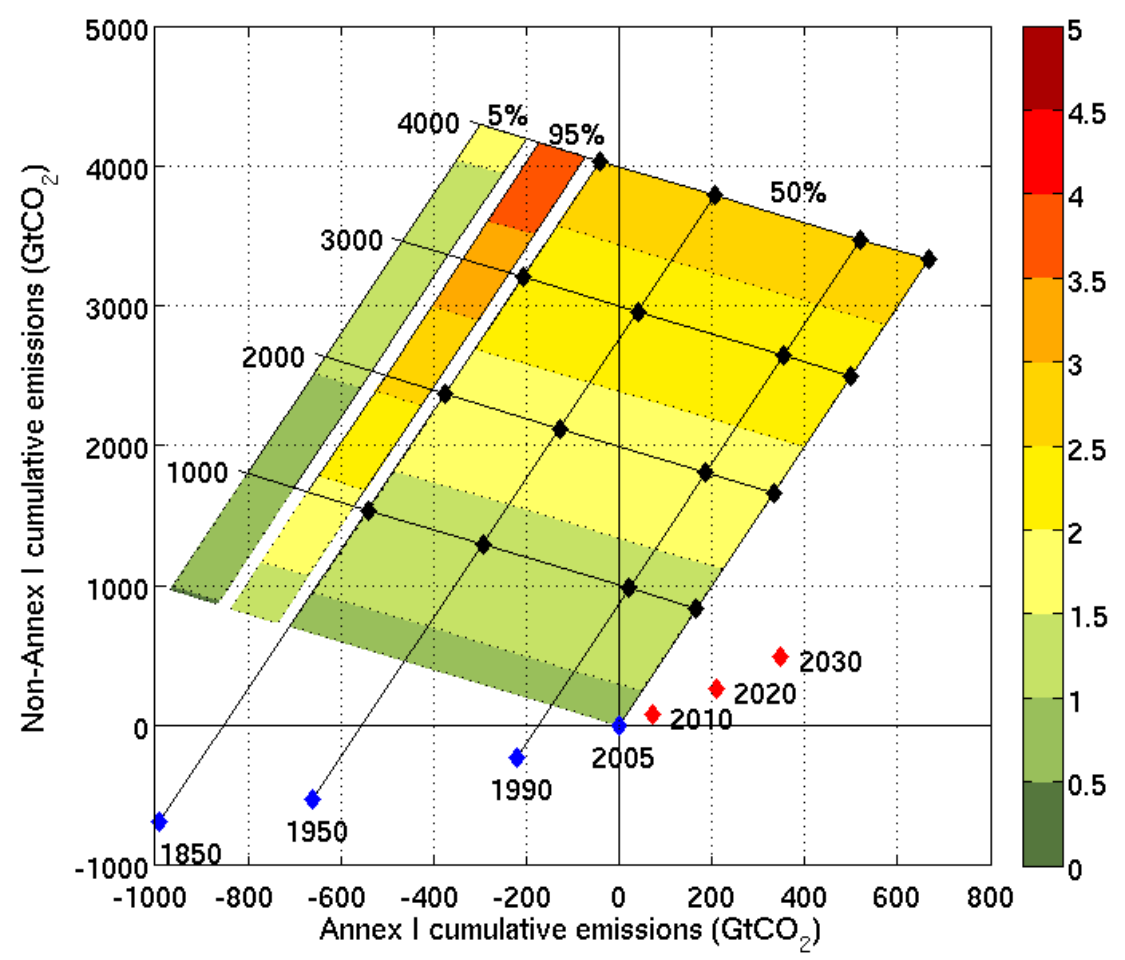

We saw in Figure 2 that the line we are now calling ECPC2005, on which the four diamonds fall, is a line through the point $(0,0)$ with a slope of 5 (reflecting the population ratio). The corresponding line associated with one of the earlier start dates is obtained by shifting the starting point of the fairness line from $(0,0)$ to the point in the lower-left quadrant whose coordinates are the negative values that, in magnitude, equal the pair of past emissions shown for the corresponding row in Table 2. For example, for 1950 , the starting point is $\left(-660 \mathrm{GtCO}_{2},-530 \mathrm{GtCO}_{2}\right)[32]$.

There are 16 intersections in Figure 3, each shown as a black diamond at an intersection of one of the four ECPC fairness lines with one of the four safety lines discussed in the previous section. (The right-most four points are the same as those highlighted in Figure 2.) Figure 3 also shows the uncertainty range in temperature rise - the color coded background under these points shows the average (labeled 50\%) increase in temperature, while the color change in the two bars at the left show the temperatures that span the very likely $(5 \%-95 \%)$ range. 
The 16 intersections span a large carbon space for trade-off between safety and fairness. Climate safety increases as one moves down-left, fairness increases as one moves up-left, and depth of reach of history increases as one moves left. The deeper into history one reaches in one's definition of "historical" fairness, the more difficult it becomes to resolve the fairness-safety conundrum. For example, the left-most point $\left(\mathrm{ECPC} 1850,1,000 \mathrm{GtCO}_{2}\right)$ is the point where the strongest versions of both safety and fairness are achieved at once: it results in cumulative emissions allocations of $-540 \mathrm{GtCO}_{2}$ for Annex I (and 1,540 $\mathrm{GtCO}_{2}$ for Non-Annex I); imagining ways to address such large negative emissions is one of the objectives of this paper.

It is instructive to add to Figure 3 a baseline trajectory for future emissions. The three points in red are the Energy Information Agency 'International Energy Outlook 2010' Business as Usual projections for cumulative emissions from Annex I and Non-Annex I regions for 2010, 2020 and 2030. If unabated until 2030, cumulative global emissions nearly cross the first safety line $\left(1,000 \mathrm{GtCO}_{2}\right)$. Moreover, the trajectory moves rapidly to the right, making it difficult to comply with fairness: for example, by 2020 Annex I countries exhaust their carbon budget in the case of a 2,000 $\mathrm{GtCO}_{2}$ target and an $\mathrm{ECPC} 990$ fairness principle.

The historical dimension of the ECPC principle addresses responsibility for future damage to people in developing nations caused by the past emissions of people in industrialized countries, mediated by global warming. As discussed in the Introduction, exactly equating future and past emissions is simplistic. To be sure, as developing countries pass through the early energy-intensive stages of industrialization in the pursuit of economic growth and a modern lifestyle [33,34], they will need to emit substantial quantities of carbon dioxide. But these countries will confront options that were not available to industrialized countries as they went through the same transitions at an earlier time. Notably, increased energy efficiency has been a steady feature of the past and shows every sign of continuing for the foreseeable future, enabling modern lifestyles to be achieved with less energy expenditure. Moreover, the energy system for most of the past century has become steadily less carbon-intensive, and, to the extent that this trend continues (i.e., that fossil fuel technologies become less economically attractive than low-carbon technologies), fewer carbon emissions will accompany the same economic growth. A more formal analysis would take these trends into account.

In Figure 3, several of the points of intersection to which we are calling attention involve negative emissions from Annex I. Negative emissions have two possible meanings. A later section of this paper explores a world where technologies that actually remove $\mathrm{CO}_{2}$ from the atmosphere, thereby tackling both safety and fairness, are widely deployed and "count" as negative emissions. But negative emissions can also be understood to be the result of trade in cumulative emissions, where, for example, money is paid by Annex I to Non-Annex I so that Annex I can emit more in the future and Non-Annex I can emit less. These trades produce movement down and to the right along a safety line. For example, the point at the intersection of ECPC1850 and 3,000 $\mathrm{GtCO}_{2}$, with roughly $200 \mathrm{GtCO}_{2}$ of negative cumulative emissions from Annex I, could represent actual emissions at the intersection of the same safety curve with ECPC1990, but the purchase of about $550 \mathrm{GtCO}_{2}$ by Annex I from Non-Annex I.

A market in cumulative emissions could increase economic efficiency, to the extent that it takes advantage of low-cost abatement opportunities wherever they occur. In particular, it could also hasten the arrival of low-cost green technology options in the developing world, if it results in an augmentation of the capital investments already expected to occur mostly there. 
However, it is not at all obvious that a market in cumulative emissions can become a vehicle for justice $[35,36]$. With today's large disparities in wealth and quality of governance, such a market could lead to early transactions that might be regretted later. Clearly, new, very strong institutions would be required. The experience of CDM has already revealed major problems concerning credit verification and quality certification of the projects involved [37]. Moreover, there is the issue of scale. CDM, the largest existing offset market and likely to continue in some version for years to come, is far smaller in scale than the trading that is envisioned here. It is hard to conceive of an exchange of many hundreds of $\mathrm{GtCO}_{2}$, which — as seen in Figure 3-is needed to move from ECPC2005 to ECPC1850.

\section{Minimum Cumulative Emissions after 2005}

In Figures 2 and 3, the origin (where the two axes cross) represents zero future emissions after 2005 for both Annex I and Non-Annex I. But emissions have already occurred since 2005, and further emissions are inevitable even if both Annex I and Non-Annex I climb down from their current emissions rapidly. It is useful to identify lines in the space of these figures that correspond to Minimal Cumulative Emissions (MCE) after 2005 for Annex I and Non-Annex I. The MCEs of Annex I and Non-Annex I are shown pictorially in Figure 4, panel (a), as a vertical and a horizontal line, respectively, drawn at locations that will be discussed below. The bands between the axes and these lines are forbidden outcomes, unless there is trading in cumulative emissions or (the subject of the next section and panels (b) and (c) of Figure 4) negative-emission technology arrives.

Figure 4. In panel (a), minimum cumulative emissions after 2005 (MCE), shown as a pair of solid lines, are added to Figure 3; their positions are explained in the text. In panels (b) and (c), a total of $1,000 \mathrm{GtCO}_{2}$ of negative emissions (see next section) are added to panel (a) - in two different ways: in panel (b), half are allocated to Annex 1 and half to Non-Annex 1, while all are allocated to Non-Annex 1 in panel (c). The shifted solid lines show the different allocations. The color coded background shows "average" equilibrium temperature rise (the $50 \%$ case). See Figure 3 for the corresponding color coded bands for the two bounds of "very likely" range.
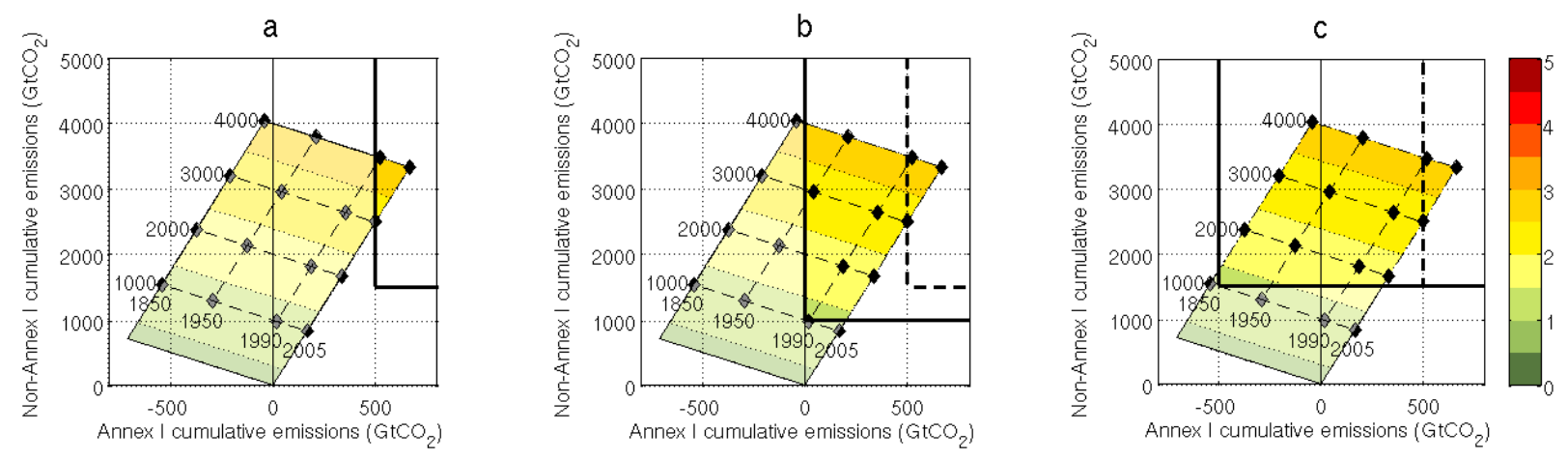

Many considerations should be accounted for in determining the positions of the MCE lines of Figure 4, panel (a). First, consider minimum global cumulative emissions. One must include the $150 \mathrm{GtCO}_{2}$ of global emissions from fossil fuels and deforestation over the past five years (for Annex I and Non-Annex I, approximately $75 \mathrm{GtCO}_{2}$ each). Also, one must allow for societal inertia, which will 
constrain emissions reduction over the next few decades. Even with great effort, the world cannot reduce its future emissions to zero instantly. Mitigation over the next few decades will be dominated by available technology options [2] and will be achieved in sectors of the economy that are known to resist change. The fossil fuel system now providing $85 \%$ of the world's primary energy will not be replaced suddenly. For example, it has been estimated that roughly $500 \mathrm{GtCO}_{2}$ will be emitted globally by the currently existing energy infrastructure over its lifetime [38].

A rough estimate of minimal future global cumulative emissions from 2005 through 2100 is provided by considering twelve energy-economy-climate models that have been evaluated in an international model-comparison exercise, EMF22 [11]. For each model, a lower bound was produced for global cumulative emissions, consistent with achieving various climate stabilization targets under alternative policy architectures and assumptions about mitigation technologies and socio-economic pathways. The publicly available EMF22 data set provides information on emissions for all Kyoto gases, land-use emissions, and $\mathrm{CO} 2$ removal from the atmosphere as a result of (i) bioenergy with carbon capture and storage (BECS), and of (ii) afforestation - two of the so-called "negative emission" technologies (see next section). In order to compute emissions gross of $\mathrm{CO}_{2}$ removal, we estimate the effect of BECS using an average coefficient of $2.5 \mathrm{GtC} / 100 \mathrm{EJ}$ [39] and also correct for afforestation. Averaging over the twelve models, minimum global cumulative emissions are $1,700 \mathrm{GtCO}_{2}$ $\left(2,500 \mathrm{GtCO}_{2}\right.$-eq when counting also non- $\mathrm{CO}_{2}$ gases [40]). For simplicity we set minimum cumulative global emissions after 2005 at $2,000 \mathrm{GtCO}_{2}$.

As for the separate lower bounds for Annex 1 and Non-Annex 1, in Figure 4, panel (a), we assign 500 to Annex I [41] and 1,500 to Non-Annex I [42]. This allocation is intended to take into account the difficulty Non-Annex I can expect to face in the short term, given the high value of fossil fuels for development at this time.

Figure 4, panel (a), reveals that only two of the 16 safe-fair points are beyond the forbidden zone, and one more is on the boundary. Trading in cumulative emissions can move all the points on the safety lines for 4,000 and 3,000 $\mathrm{GtCO}_{2}$ into the allowed region and it can move all the points on the safety line at 2,000 $\mathrm{GtCO}_{2}$ approximately to the corner where the two $\mathrm{MCE}$ lines intersect. But even with unlimited trading the points on the $1,000 \mathrm{GtCO}_{2}$ safety line cannot be brought into the feasibility space, meaning that the most stringent of our four stabilization targets remains out of reach. In short, resolving the safety-fairness conundrum is more difficult for more ambitious targets than for less ambitious ones. It is hardly surprising that the trend towards stricter targets has lead to more alarm about the potential to achieve fairness.

\section{Negative Emissions via Technology}

The pursuit of the twin goals of safety and fairness would benefit from new technologies that enable moving down and left in Figures 2, 3 and 4 in this paper. Such technologies include not only those that provide very low emissions but also those that remove $\mathrm{CO}_{2}$ from the atmosphere. Other words for $\mathrm{CO}_{2}$ removal technologies are negative-emission technologies and engineered $\mathrm{CO}_{2}$ sinks. They require manipulation of the global carbon cycle-for example, the deliberate transfer of $\mathrm{CO}_{2}$ from the atmosphere to plants, soil, ocean, or deep underground in porous rock formations. 
Among the proposed technological approaches are (1) biological sequestration of carbon in forests and soils, (2) $\mathrm{CO}_{2}$ capture while processing biomass for power and fuels, followed by $\mathrm{CO}_{2}$ sequestration below ground, (3) biological $\mathrm{CO}_{2}$ removal from the atmosphere at the ocean surface (e.g., using plankton), and (4) direct air capture of $\mathrm{CO}_{2}$ using chemical absorbers. There is no assurance that technologies of this kind can be deployed in this century at the scale required, nor that the concomitant, nearly complete decarbonization of the economy can be achieved. Costs are key and hard to predict, since none of these technologies has been commercialized. There are also major uncertainties regarding the effectiveness, costs, and environmental impacts of $\mathrm{CO}_{2}$ removal technologies $[43,44]$.

The figures in this paper suggest that a useful scale for "globally significant" removal of $\mathrm{CO}_{2}$ from the atmosphere is the removal of $1,000 \mathrm{GtCO}_{2}$. In Figure 4, panels (b) and (c), we consider two arbitrary assignments of $1,000 \mathrm{GtCO}_{2}$ of negative emissions. In panel (b) the shares are equal: 500 $\mathrm{GtCO}_{2}$ to Annex I and $500 \mathrm{GtCO}_{2}$ to Non-Annex I. By contrast, in panel (c) all negative emissions are assigned to Annex 1. The 500:500 allowance exactly compensates Annex I for its minimum cumulative emissions, bringing the vertical MCE line back to the vertical axis and resulting in eight safe-fair pairs becoming "allowed"-all those with positive net cumulative emission allowances for Annex I. (Two 1,000 $\mathrm{GtCO}_{2}$ points are excluded-just barely.) The alternative allowance, which assigns industrialized countries the whole carbon dioxide removal program, produces twelve safe-fair pairs (there are four more allowed points in panel (c) than in panel (b)), largely because that allocation scheme assigns the effort to a smaller share of population.

How to assign any specific negative emissions undertaking to any specific country, or even to Annex I vs. Non-Annex I, is not at all clear. Should the allocation depend on who pays or where the program is hosted, for example? At present, deforestation and afforestation are credited in carbon accounting to the country whose land is affected. However, another accounting scheme is under development, as financial transfers from industrialized countries to developing countries are considered that would fund carbon-motivated forest management in developing countries while crediting emissions reductions to industrialized countries. As for $\mathrm{CO}_{2}$ removal efforts that occur within the global commons rather than within national boundaries, such as $\mathrm{CO}_{2}$ transfer from the atmosphere to the ocean, it would seem that only an allocation based on who pays could make sense.

The sequestration of $1,000 \mathrm{GtCO}_{2}$ from the atmosphere would require huge investments and innovation. In many versions, associated land or ocean impacts would be central concerns. The $1,000 \mathrm{GtCO}_{2}$ absorption task, if assigned to the second half of this century, translates into a removal rate of $20 \mathrm{GtCO}_{2}$ per year, which is two-thirds of the emissions rate today [45].

\section{Conclusions}

In this paper we have provided a framework for thinking quantitatively about the trade-off between climate safety and fairness. Both matter, since goal setting and equity are intertwined in international climate change negotiations [46-48]. We associate levels of safety with cumulative global emissions. The starting point of our fairness principle is a view of the atmosphere as a common-property resource belonging equally to everyone in the world. The result is that an extra five tons of $\mathrm{CO}_{2}$ of emissions are allowed in Non-Annex I for each extra ton of $\mathrm{CO}_{2}$ emissions allowed in Annex I. This definition 
can also be extended back into the past, thereby combining the concepts of a right to emit and historical responsibility. This is in line with some recent analyses and policy proposals, but it is hardly unique. Many alternative definitions of fairness can be devised, expressing many alternative formulations of global justice and its application to climate change [49].

We have introduced a few simple concepts, along with rough estimates of their magnitudes, to promote quantitative discussion. Minimum Cumulative Emissions (MCE) capture the reality of longlived energy infrastructure, current emissions-reduction commitments, and the lead long times required to develop alternatives to replace the current fossil-energy infrastructure. We estimate global Minimum Cumulative Emissions (MCE) at 2,000 $\mathrm{GtCO}_{2}$ and find that these emissions (in the absence of the deployment of negative emissions technology) already limit the chance of avoiding a $2{ }^{\circ} \mathrm{C}$ temperature rise to just above $50 \%$ (see Table 1). When we further assign these $2,000 \mathrm{GtCO}_{2}$ of global emissions so that $500 \mathrm{GtCO}_{2}$ go to Annex I and $1,500 \mathrm{GtCO}_{2}$ go to Non-Annex I, and restrict our attention to the $2,000 \mathrm{GtCO}_{2}$ safety line, none of our four fairness conditions is satisfied (see Figure 4). For this case even ECPC2005 (which ignores all emissions prior to 2005 and is the most limited of the four visions of fairness) is inconsistent with an $\mathrm{MCE}$ for Annex 1 of $500 \mathrm{GtCO}_{2}$, since it allows Annex 1 only onesixth of future emissions, or $330 \mathrm{GtCO}_{2}$ in this case. To realize even ECPC2005, $170 \mathrm{GtCO}_{2}$ of NonAnnex I cumulative emissions would need to be purchased by Annex I.

Invoking the possibility of realizing $1,000 \mathrm{GtCO}_{2}$ of negative emissions and changing no other assumptions, the chance of avoiding a $2{ }^{\circ} \mathrm{C}$ temperature rise exceeds $95 \%$. A larger fraction of the targets are accessible and stricter ECPC rules are allowed under this technology scenario, though the exact consequences for fairness depend on how negative emissions are assigned. However, achieving $1,000 \mathrm{GtCO}_{2}$ of negative emissions via engineered sinks will require a combination of monumental investment and extraordinary innovation. At present there is no reason to expect cheap, environmentally attractive, and scalable versions of these technologies to make a timely entrance into the space of options. As a consequence, counting on these technologies to provide the path to the simultaneous realization of safety and fairness is unwise.

Our mapping also considers future cumulative global emissions that exceed 2,000 $\mathrm{GtCO}_{2}$, specifically 3,000 and 4,000 $\mathrm{GtCO}_{2}$. Higher emissions, of course, push the world into less safe territory. Figure 4, panel (a), confirms that, when no historical emissions are counted (ECPC2005), the 500-2,500 split of 3,000 $\mathrm{GtCO}_{2}$ of global emissions allocates to Annex 1 exactly its estimated minimal cumulative emissions. Stronger fairness conditions are only realizable with trading - as much as $700 \mathrm{GtCO}_{2}$ of exchange for "full" historical responsibility (ECPC1850).

The recent trend towards stricter targets (more "safety"), associated with further developments in climate science and the rapid rise in global emissions in the recent past, has yet not taken cognizance of its impacts on various criteria of fairness. Our paper shows quantitatively, however, just how difficult meeting both objectives actually is, when a narrow definition of fairness in terms of equal per capita shares of global emissions is reconciled with stringent climate stabilization targets. Adding historical responsibility to the definition of fairness makes the reconciliation substantially more difficult. And all targets become harder to meet if emissions continue unabated for another 10 or 20 years. The challenges for both developed and developing countries, in this calculus, are immense.

We wish again to alert the reader to the shortcomings of a definition of fairness in terms of per capita access to the atmosphere for individual emissions. Associating equity with the right to emit $\mathrm{CO}_{2}$ 
inadequately captures the more critical right of everyone to seek and achieve a higher standard of living. Once climate change is seriously addressed, priority will be given to reducing the $\mathrm{CO}_{2}$ emissions associated with any given level of human welfare. Throughout the future global economy, less energy will be required to achieve the same amenity (mobility or comfort, for example) and lower carbon emissions will accompany the same energy expenditures. Such trends will not eliminate the difficult trade-offs between safety and equity, but they will weaken them.

The formalism presented here for dealing with historical emissions equates $\mathrm{CO}_{2}$ emissions entitlements at all times - a convenient first step whose principal virtue is simplicity. Especially important for the further development of our approach would be a more sophisticated accounting for the steady lowering through time of the $\mathrm{CO}_{2}$ emissions required for the satisfaction of human needs. We strongly encourage an exploration of alternative conceptualizations of the historical dimensions of equity that take the evolution of relevant features the global economy into account.

To summarize, our investigation shows the interplay of safety and fairness under different assumptions about historical emissions, trading in cumulative emissions, residual emissions, and negative emissions. It is meant to provide an instructive tool to treat safety and fairness simultaneously when exploring the problem of international burden-sharing. The figures in our paper provide a reality check on the reader's preferences regarding safety and fairness. Our intention is to encourage iteration over such preferences.

\section{Acknowledgments}

This paper has its origins in a private communication from Nicolas Stern about our earlier paper [16], which urged us to pay greater attention to "historical responsibility". In the course of writing the present paper, we have benefited from critical readings by Robert Keohane and M. V. Ramana. Support for the endeavor was provided by the Carbon Mitigation Initiative at Princeton University, funded by BP. We also thank an unnamed referee for many good recommendations, and for asking us to clarify and sharpen our definition of fairness.

\section{Conflict of Interest}

The authors declare no conflict of interest.

\section{References and Notes}

1. Stern, N. Key Elements of a Global Deal on Climate Change; LSE Research Online Monograph (Discussion Paper); London School of Economics and Political Science: London, UK, 2008. Available online: http://eprints.lse.ac.uk/19617/ (accessed on 10 June 2010)

2. Pacala, S.; Socolow, R. Stabilization wedges: Solving the climate problem for the next 50 years with current technologies. Science 2004, 305, 968-972

3. This assumption allows us to ignore the big uncertainties regarding the measurement of non $\mathrm{CO}_{2}$ gases and aerosols, and their compensating effects on forcing.

4. Climate Analysis Indicators Tool (CAIT). World Resources Institute: Washington, DC, USA. Available online: http://cait.wri.org (accessed on 10 May 2010) 
5. Houghton, R.A. Carbon Flux to the Atmosphere from Land-Use Changes: 1850-2005. In TRENDS: A Compendium of Data on Global Change; Carbon Dioxide Information Analysis Center, Oak Ridge National Laboratory, U.S. Department of Energy: Oak Ridge, TN, USA, 2008. Available online: http://cdiac.ornl.gov/trends/landuse/houghton/houghton.html (accessed on 12 January 2010)

6. Committee on Stabilization Targets for Atmospheric Greenhouse Gas Concentrations, National Research Council. Climate Stabilization Targets: Emissions, Concentrations, and Impacts over Decades and Millenia; The National Academies Press: Washington, DC, USA, 2011.

7. The National Academies report [6] recommends a multiplicative coefficient 1,000 GtC of cumulative emissions per $1.75{ }^{\circ} \mathrm{C}$ of maximum temperature rise. It also provides a "very likely" range (centered range containing $90 \%$ of the distribution), where $1,000 \mathrm{GtC}$ of cumulative emissions produce a temperature rise between $1.0^{\circ} \mathrm{C}$ and to $2.5^{\circ} \mathrm{C} .1 \mathrm{GtC}$ contains the same amount of carbon as $11 / 3 \mathrm{GtCO}_{2}$.

8. The approach adopted here, moving directly between cumulative emissions and temperatures and thereby finessing concentrations, recognizes that temperature, rather than concentration, ultimately determines the impacts of climate change. Climate models enable the tracking of concentration and temperature trajectories associated with any emissions trajectory and the inclusion of other greenhouse gases. When we use MAGICC, with an emissions trajectory restricted to the 21 st century, we find that cumulative $\mathrm{CO}_{2}$ emissions produce a temperature response in 2100 near the top-5\% boundary.

9. van Vuuren, D.; den Elzen M.; Lucas P.; Eickhout, B.; Strengers, B.; van Ruijven, B.; Wonink, S.; van Houdt, R. Stabilizing greenhouse gas concentrations at low levels: An assessment of reduction strategies and costs. Clim. Change 2007, doi:10.1007/s/10584-006-9172-9.

10. RCP Database (version 2.0), IIASA Models and Databases. Available online: http://www.iiasa.ac.at/web-apps/tnt/RcpDb/dsd?Action=htmlpage\&page=welcome (accessed on 10 May 2010).

11. Clarke, L.E.; Edmonds, J.A.; Krey, V.; Richels, R.G.; Rose, S.; Tavoni, M. International climate policy architectures: Overview of the EMF22 International scenarios. Ener. Econ. 2009, 31, S64-S81.

12. The reader is cautioned that the fairness assessment presented here is workable only for a limited set of ways of dividing the world into political units.

13. Department of Economic and Social Affairs, United Nations. World Population Prospects, The 2010 Revision; 2010. Available online: http://esa.un.org/unpd/wpp/index.htm (accessed on 22 October 2010).

14. Meyer, A. Contraction \& Convergence; Green Book Ltd.: Dartington, UK, 2000.

15. Posner, E.A.; Sunstein, C.R. Justice and Climate Change; Discussion Paper 08-04; Harvard Project on International Climate Agreements, Belfer Center for Science and International Affairs, Harvard Kennedy School: Cambridge, MA, USA, 2008.

16. Chakravarty, S.; Chikkatur, A.; deConinck, H.; Pacala, S.; Socolow, R.; Tavoni, M. Sharing global $\mathrm{CO}_{2}$ emission reductions among one billion high emitters. Proc. Natl. Acad. Sci. USA 2009, 106, 11884-11888. 
17. Baer, P.; Athanasiou, T.; Kartha S.; Kemp-Benedict, E. The Greenhouse Development Rights Framework: The right to development in a climate constrained world. Available online: http://www.ecoequity.org/docs/TheGDRsFramework.pdf (accessed on 4 January 2012)

18. Agarwal, A.; Narain, S. Global Warming in an Unequal World: A Case of Environmental Colonialism; Centre for Science and Environment: New Delhi, India, 1991.

19. Baer, P.; Harte, J.; Haya, B.; Herzog, A.V.; Holdren, J.; Hultman, N.E.; Kammen, D.M.; Norgaard, R.B.; Raymond, L. Equity and Greenhouse Gas Responsibility. Science 2000, 289, doi:10.1126/science.289.5488.2287.

20. Sagar, A.D. Wealth, Responsibility, and Equity: Exploring an Allocation Framework for Global GHG Emissions. Clim. Change 2000, 45, 511-527.

21. Neumayer, E. In defense of historical accountability for greenhouse gas emissions. Ecol. Econom. 2000, 33, 185-192.

22. Grasso, M. A normative ethical framework in climate change. Climatic Change 2007, 81, 223-246.

23. Bode, S. Equal emissions per capita over time-A proposal to combine responsibility and equity of rights. Eur. Environ. 2004, 14, 300-316.

24. Pan, J. Carbon budget for basic needs satisfaction: Implications for international equity and sustainability. World Econom. Politics 2008, 1, 35-42.

25. Ding, Z.L.; Duan X.N., Ge, Q.S.; Zhang, Z.Q. Control of atmospheric $\mathrm{CO}_{2}$ concentrations by 2050: A calculation on the emission rights of different countries. Sci. China Ser. D Earth Sci. 2009, 52, 1447-1469.

26. He, J.; Chen, W.; Teng, F.; Liu, B. Long-term climate change mitigation target and carbon permit allocation. Adv. Clim. Change Res. 2009, 5(Suppl.), 78-85.

27. Kanitkar, T.; Jayaraman, T.; D’Souza, M.; Purkayastha, P.; Raghunandan, D.; Talwar, R. How much 'carbon space' do we have? Physical constraints on India's climate policy and its implications. Econ. Pol. Weekly 2009, 44, 41-42.

28. Kanitkar, T.; Jayaraman, T.; D’Souza, M.; Sanwal, M.; Purkayastha, P.; Talwar, R.; Raghunandan, D. Meeting Equity in a Finite Carbon World. In Proceedings of Global Carbon Budgets and Burden Sharing in Mitigation Actions, Mumbai, India, 28-29 June 2010. Available online: http://moef.nic.in/downloads/public-information/tiss-conference-cc-2010.pdf. (accessed on 13 September 2010)

29. German Advisory Council on Global Change (WBGU). Solving the Climate Dilemma: The Budget Approach, 2009. Available online: http://www.wbgu.de/wbgu_sn2009_en.pdf (accessed on 22 June 2010).

30. Oberheitmann, A. A new post-Kyoto climate regime based on per-capita cumulative $\mathrm{CO}_{2}$-emission rights - Rationale, architecture and quantitative assessment of the implication for the $\mathrm{CO}_{2}$-emissions from China, India and the Annex-I countries by 2050. Mitigat. Adapt. Strat. Global Change 2010, 15, 137-168. 
31. Since $1850,75 \%$ of Annex I emissions have come from energy use and $25 \%$ from land-use change. The corresponding figures for Non-Annex I countries are $40 \%$ and $60 \%$. One third of the emissions from deforestation in Non-Annex I occurred before 1950; the fact that many Non-Annex I countries were colonies adds an ethical dimension that could be addressed. The ECPC1850 principle, which incorporates the most historical emissions, is often used as a marker by developing countries (For example, [26]).

32. The negative values reflect the choice of 2005 as the starting point $(0,0)$ for future cumulative emissions, since past emissions have a negative sign with respect to this point. All values are positive if cumulative emissions are defined to start in 1850.

33. Grubb, M. Seeking fair weather: Ethics and the International debate on climate change. Int. Aff. 1995, 71, 463-496.

34. Shukla, P.R. Justice, Equity and Efficiency in Climate Change: A Developing Country Perspective. In Fair Weather? Equity Concerns in Climate Change; Toth, F., Ed.; Earthscan: London, UK, 1999.

35. Eckersley, R. Just Carbon Trading? In Climate Change and Social Justice; Moss, J., Ed.; Melbourne University Press: Melbourne, Australia, 2009.

36. Ott, H.E.; Sachs, W. The Ethics of International Emissions Trading. In Ethics, Equity, and International Negotiations on Climate Change; Pinguelli-Rosa, L., Munasinghe, M., Eds.; Edward Elgar Publishing: Cheltenham, UK, 2002.

37. Wara, M.W.; Victor, D.G. A Realistic Policy on International Carbon Offsets; Working Paper No. 74; Program on Energy and Sustainable Development, Stanford University, 2008. Available online: http://pesd.stanford.edu/publications/a_realistic_policy_on_international_carbon_offsets (accessed on 19 June 2010)

38. Davis, S.J.; Caldeira, K.; Matthews, H.D. Future $\mathrm{CO}_{2}$ emissions and climate change from existing energy infrastructure. Science 2010, 329, 1330-1333.

39. Azar, C.; Lindgren, K.; Obersteiner, M.; Riahi, K.; van Vuuren, D.P.; den Elzen, M.G.J.; Möllersten, K.; Larson, E.D. The feasibility of low $\mathrm{CO}_{2}$ concentration targets and the role of bio-energy with carbon capture and storage (BECCS). Clim. Change 2010, 100, 195-202.

40. For each model, we compute the minimum cumulative global emissions (2005-2100) across the various scenarios. This procedure could somewhat overestimate the lowest carbon budget attainable by each model since only a subset of climate stabilization targets was explored (450eq, $550 \mathrm{eq}, 650 \mathrm{eq})$. Yet, the most stringent one (450e) is very demanding, thus producing a quite low bound.

41. This estimate of the MCE for Annex I can be understood as follows: (1) One starts with the $75 \mathrm{GtCO}_{2}$ emitted over the past five years. (2) One takes seriously the goals enunciated recently by many Annex I governments that require approximately a linear descent to an $80 \%$ emission reduction relative to 2010 values by 2050 , thereby averaging $9 \mathrm{GtCO}_{2} / \mathrm{yr}$ over 40 years and adding another $360 \mathrm{GtCO}_{2}$ to cumulative emissions. The emissions rate for Annex I in 2050, $3 \mathrm{GtCO}_{2} /$ year, is $2 \mathrm{tCO}_{2} /$ capita. (3) One further assumes that emissions fall (linearly) by another factor of two in the second half century to $1.5 \mathrm{GtCO}_{2} /$ year $\left(1 \mathrm{tCO}_{2} /\right.$ capita $)$, contributing another 112.5 $\mathrm{GtCO}_{2}$. Rounding off, the sum of these three contributions results in an MCE for Annex I of about $500 \mathrm{GtCO}_{2}$. 
42. This estimate of the MCE for Non-Annex I can be understood as follows: (1) One starts with the $75 \mathrm{GtCO}_{2}$ emitted over the past five years. (2) One assumes an emissions trajectory from 2010 to 2050 that allows for growth in fossil fuel emissions before a decline sets in. Non-Annex I emissions rise linearly from $15 \mathrm{GtCO}_{2}$ in 2010 to $20 \mathrm{GtCO}_{2}$ in 2030 and then decline linearly to return in 2050 of $15 \mathrm{GtCO}_{2}$, or $2 \mathrm{tCO}_{2}$ per capita, the same value per capita in that year as for Annex I. (3) One assumes a subsequent linear decline from 2050 to 2100 along a path with the same per capita values as for Annex I, thereby falling to $7.5 \mathrm{GtCO}_{2}$ in 2100 , adding another $562.5 \mathrm{GtCO}_{2}$. Rounding off the sum, upward, results in an MCE for Non-Annex I of roughly $1,500 \mathrm{GtCO}_{2}$.

43. Royal Society. Geoengineering the Climate: Science, Governance and Uncertainty; 2009. Available online: http://royalsociety.org/geoengineeringclimate/_(accessed on 9 May 2010)

44. American Physical Society. Direct Air Capture of $\mathrm{CO}_{2}$ with Chemicals; 2011. Available online: http://www.aps.org/policy/reports/popareports/loader.cfm?csModule=security/getfile\&PageID=24 4407_(accessed on 7 June 2011)

45. Note that, in general, removal of $1 \mathrm{tCO}_{2}$ from the atmosphere does not result in exactly one ton of reduction in atmospheric $\mathrm{CO}_{2}$, because it will be accompanied by adjustments in the oceans and vegetation to a changed atmospheric concentration. At the ocean surface, dissolved $\mathrm{CO}_{2}$ will be transferred to the atmosphere, undoing some of the removal; other effects (deep ocean currents, forest responses) are more difficult to predict.

46. Heyward, M. Equity and International climate change negotiations: A matter of perspective. Clim. Policy 2007, 7, 518-534.

47. den Elzen, M.; Hohne, N. Reductions of greenhouse gas emissions in Annex I and Non-Annex I countries for meeting concentration stabilisation targets. Clim. Change 2008, 91, 249-274.

48. Ding Z.L.; Duan X.N.; Ge, Q.S; Zhang, Z.Q. On the major proposals for carbon emission reduction and some related issues. Sci. China Ser. D Earth Sci. 2010, 53, 159-172.

49. Bodansky, D. International Climate Efforts Beyond 2012: A Survey of Approaches; prepared for the Pew Center on Global Climate Change, 2004. Available online: http://www.pewclimate.org/ docUploads/2012\%20new.pdf (accessed on 29 June 2011).

(C) 2012 by the authors; licensee MDPI, Basel, Switzerland. This article is an open access article distributed under the terms and conditions of the Creative Commons Attribution license (http://creativecommons.org/licenses/by/3.0/). 